of the BDJ, also demonstrates the value of frank opinion sharing in ongoing peer review in scientific publishing for the benefit of all. DOI: 10.1038/sj.bdj.2016.72

1. European Society of Endodontology. Quality guidelines for endodontic treatment: consensus report of the European Society of Endodontology. Int Endod J2006: 39: 921-930.

2. Ng Y L, Mann V, Gulabivala K. A prospective study of the factors affecting outcomes of non-surgical root canal treatment; part 1: periapical health. Int Endod J 2011: 44: 583-609.

3. Di Filippo G, Sidhu S K, Chong B S. Apical periodontitis and the technical quality of root canal treatment in an adult sub-population in London. BrDent J 2014; 216: E22.

\section{Accidental cheek fistula}

Sir, a 49-year-old male patient with no systemic medical history other than controlled diabetes came to the Department of Dentistry, Jeju National University Hospital. The patient underwent intraoral incision and drainage for swelling on the right side of his face that began to develop a year previously. Due to a relapse, the patient was prescribed with antibiotics from a local clinic. But as his condition did not heal, the patient was referred to the department of dermatology, then to plastic surgery and dentistry.

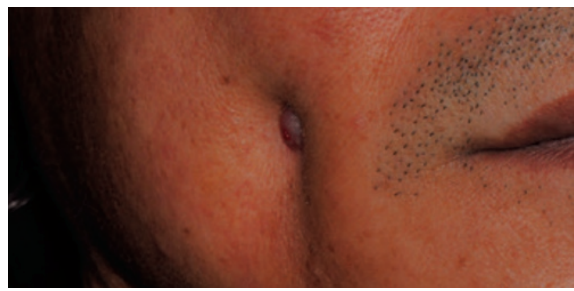

Fig. 1 Fistula formed through the skin

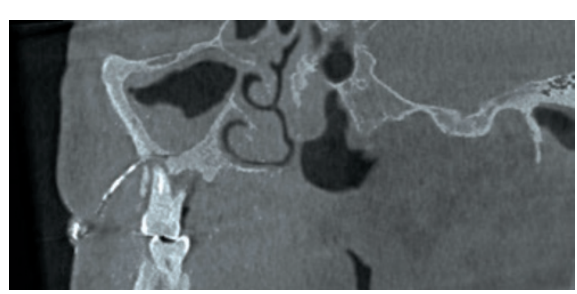

Fig. 2 Accidental tracing with calcium hydroxide agent in CBCT image

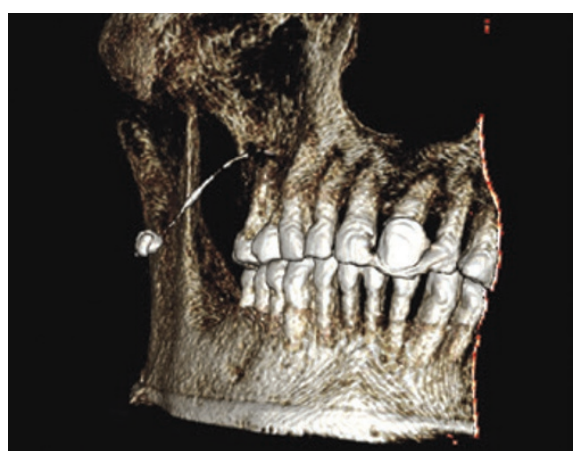

Fig. 3 Accidental tracing with calcium hydroxide agent in 3D image
A protruding lesion was observed around the retracted skin on the right cheek of the patient (Fig. 1). In the intraoral radiographic imaging, a dilated root lesion of dental origin in the maxillary first molar tooth was seen and the patient was diagnosed with buccal fistula of dental origin, and was given endodontic treatment. A water-soluble agent made of calcium hydroxide was applied to control the root canal infection. In a cone beam CT image conducted to check for the presence of maxillary sinus infection, the pushed-out agent showed a sinus tract from the tooth root to the buccal fistula (Figs 2-3).

There were no side effects due to the pushed out agent and all symptoms disappeared within four months of the conservative endodontic treatment. The fistula was obliterated and a scar formed (Fig. 4).

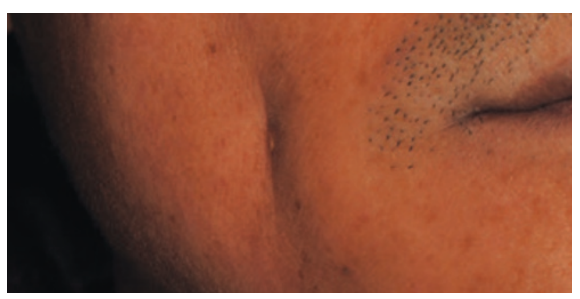

Fig. 4 Healing of fistula with scar

Se Hoon Kahm, Sung-Joon Kim, Korea DOI: 10.1038/sj.bdj.2016.73

\section{DENTAL VOLUNTEERING}

\section{Rewarding and affirming}

Sir, I have recently returned to the UK following four months in East Africa volunteering my dental skills. People in developing countries can have daily struggles against all kinds of adversity including securing shelter, finding food for their families and paying for school fees - so let's make toothache one less thing for them to worry about.

Dental volunteering should not just be for undergraduate students on elective. Experienced clinicians have a great deal to offer and don't need any specialist skills. In countries with limited dental services, patients present in chronic pain of many years' duration, with recurrent infections and externally draining fistulas as well as more routine problems which would otherwise go untreated. In the countries where I worked, antibiotics were freely available without a prescription and over-used repeatedly in the absence of basic definitive treatment. I found that most patients displayed an unflinching resilience during treatment; they responded enthusiastically to preventive advice and showed their appreciation with gifts such as crates of mangoes and fresh fish.
I call to action the UK dental profession to do our part in easing the lives of those in developing countries. Yes, there are financial implications; however, fundraising opportunities exist and loyal patients from the UK are often willing to donate to the cause if made aware of it. Flight expenses aside, the cost of daily living in most developing countries is minimal. The opportunities available range from basic extraction camps, care in practice or hospital settings to sustainable teaching programmes. Dental charities operate in Africa, Asia, South America, Palestine and even Afghanistan. Dentists, dental therapists and dental nurses are welcomed in positions lasting from two weeks to two years.

With the daily frustrations of dentistry in the UK, it's rewarding and affirming to work where our skills are highly needed and appreciated. The experience has certainly reminded me why I wanted to work in dentistry in the first place.

M. Young, Edinburgh DOI: 10.1038/sj.bdj.2016.74

\section{DENTAL PUBLIC HEALTH}

\section{The late Professor Aubrey Sheiham}

Sir, dental public health and indeed health promotion in general has lost a resolute champion with the passing of Professor Aubrey Sheiham. His contribution to this field has been enormous and many, like ourselves, will miss his great enthusiasm for and critical analysis of this vital field.

When the UK Health Education Council together with the British Association for the Study of Community Dentistry convened a meeting in 1975 to define and establish a scientific basis for dental health education, Aubrey Sheiham was one of the experts involved. The meeting led to the publication of the first edition of the Scientific Basis of Oral Health Education and with great enthusiasm he acted as a scientific advisor to all successive editions. Indeed when invitations were sent out to join the scientific advisory panel, Aubrey was always the first to respond.

We will greatly miss his staunch support for this document, which for 40 years has benefited from his sound advice. We would also like to note, with gratitude, his role advising the former Health Education Authority on dental public health for part of its existence.

R. S. Levine OBE, Leeds; C. Stillman-Lowe, Reading DOI: 10.1038/sj.bdj.2016.75

Editor-in-Chief's note: An obituary for Professor Sheiham is published in this issue. 